\title{
Work disruptions of electronics devices in hospital objects
}

\section{Suproniuk, Z. Skibko, A. Stachno}

M. Suproniuk, Z. Skibko, A. Stachno, "Work disruptions of electronics devices in hospital objects," Proc. SPIE 11442, Radioelectronic Systems Conference 2019, 114421I (11 February 2020); doi: 10.1117/12.2564709

SPIE. Event: Radioelectronic Systems Conference 2019, 2019, Jachranka, Poland 


\title{
WORK DISRUPTIONS OF ELECTRONICS DEVICES IN HOSPITAL OBJECTS
}

\author{
M. Suproniuk*a ${ }^{*}$ Z. Skibko ${ }^{\mathrm{b}}$, A. Stachno ${ }^{\mathrm{c}}$ \\ ${ }^{a}$ Military University of Technology, Kaliskiego 2, Warsaw, 00-908, Poland; \\ bialystok University of Technology, Wiejska 45D, Bialystok, 15-351, Poland; \\ ${ }^{c}$ Wroclaw University of Science and Technology, Janiszewskiego 11/17, Wroclaw, 50 - 370 , \\ Poland;
}

\begin{abstract}
With the development of technology, there is an increase in the industry of sensitive devices which work is dependent on parameters of electricity from which they are supplied. This aspect is especially important for example in hospitals, where health and human life often depend on the correct work of electronics devices. The article presents - on the selected practical example - parameters describing the electricity supplying the hospital facility. In that hospital the incorrectly operation of the magnetic resonance has been observed. The analyzed facility is powered from the medium voltage network via its own $15 / 0,4 \mathrm{kV}$ transformer station. Based on changes in recorded waveforms of physical quantities in time, it was noticed that the loads installed there significantly impact on the quality of the electricity which are supplied. One of the figures presents value of the waveform of the total harmonic distortion coefficient of the voltage, which is dependent on value of the load's current. Based on the recorded parameters describing the quality of electricity supplying the prospected hospital, possible technical solutions have been proposed. They can directly contribute to the elimination of interference, and thus guarantee the proper work of the equipment set there.
\end{abstract}

Keywords: interference in the operation of electronic devices, quality of electricity, voltage distortion, voltage fluctuations

\section{INTRODUCTION}

The application range of electronic devices is growing along with the development of technology. Unfortunately, due to the specific nature of their operation (most often they are fed by lowered/converted voltage), they frequently have an adverse impact on the quality parameters of electricity, which affect the operation of numerous devices and systems today [1]. Changes in the values or waveforms of the supply voltage do not remain neutral to the operation of other devices that are sensitive to them. The correct operation of electronic devices becomes particularly important in situations, where they are a base for making decisions impacting human health or life. In this research paper, the Authors presented a case study, in which one of hospitals reported incorrect operation of newly installed magnetic resonances (MRI). The building in question is fed from a $15 \mathrm{kV}$ line, through its own MV/LV transformer-switchgear station. The system comprised two coupled $400 \mathrm{kVA}$ transformers (each supplied from an RPZ-district supply point via a separate cable line), though only one of the transformers was operated under normal conditions (the second one was without load, as a power supply backup). The transformer LV side was coupled to busbars of the RGnn (LV switchgear), used to supply individual consumers (including MRIs).

\section{PARAMETERS DESCRIBING THE QUALITY OF ELECTRICITY}

\subsection{Fundamental knowledge}

The quality of electricity is a set of parameters describing the process of supplying power to consumers under normal operating conditions. They, in particular, characterize the supply voltage and consumer supply continuity. Some of the parameters describing the quality of electricity are standardized and they include the following:

- $\quad$ supply network frequency,

*marek.suproniuk@wat.edu.pl; wel.wat.edu.pl;

Radioelectronic Systems Conference 2019, edited by Piotr Kaniewski, Jan Matuszewski, Proc. of SPIE Vol. 11442, 114421I - (C) 2020 SPIE · CCC code: 0277-786X/20/\$21 - doi: 10.1117/12.2564709 
- voltage deviations (slow voltage changes),

- voltage fluctuations (rapid voltage changes),

- light flicker indicator,

- voltage unbalance,

- voltage harmonics.

In Poland, the requirements regarding the quality of electricity have been described in three documents:

- Regulation of the Minister of Economy of 4 May 2007 on the detailed functioning conditions of the electromagnetic system [2],

- PN-EN 50160:2010. Voltage characteristics of electricity supplied by public electricity networks,

- Distribution Grid Operating and Maintenance Manual (approved by a decision by the President of URE Energy Regulatory Office dated 10 September 2013).

Legal regulations set out in the aforementioned documents apply only to normal operating conditions, namely, when the electricity demand is covered by generated power and the damage is eliminated automatically by the protection I\&C system, with a simultaneous lack of conditions, which primarily include:

- grid operation in temporary supply systems,

- non-conformity of the consumer systems or equipment with appropriate standards or technical requirements regarding consumer incorporation,

- extraordinary situations beyond the control of the supplier.

This paper presents only these parameters describing the quality of electricity, in regard to which significant deviations from normative values had been observed.

\subsection{Rapid and slow voltage value changes}

Supply voltage value changes are slow (called voltage deviations) or rapid (called voltage fluctuations) increases or decreases in the voltage value, usually resulting from load changing within a given power system.

Voltage deviations are calculated from the relationship [4]:

$$
\begin{gathered}
\Delta U=U-U_{n} \\
\Delta U_{\%}=\frac{\Delta U}{U_{n}} 100 \%
\end{gathered}
$$

where: $U$ - actual voltage value, $U_{n}$ - rated voltage value.

According to currently applicable regulations [2-4], the values from a set of 10-minute average voltage values shall fall within a range of $U_{n} \pm 10 \%$ for $95 \%$ of the week.

Indicators, which characterized voltage fluctuations of consumer terminals include:

- voltage fluctuation amplitude, described by the relationship:

$$
\begin{gathered}
\Delta U=U\left(t_{1}\right)-U\left(t_{2}\right) \\
\mathrm{d}=\frac{\Delta U}{U_{\mathrm{n}}} 100 \%
\end{gathered}
$$

where: $U\left(t_{1}\right)$ - instantaneous voltage effective value $t_{1}, U\left(t_{2}\right)$ - actual instantaneous voltage value $t_{2}, d$ - relative voltage change.

- voltage fluctuation amplitude frequency, or in the case of periodic fluctuations - voltage fluctuation frequency;

- short-term light flicker indicator $P_{s t}$ (which determines the short-term light flicker nuisance, in the order of several minutes). $P_{s t}=1$ is a conventional light flicker nuisance threshold;

- long-term light flicker indicator $P_{l t}$ (which determines the long-term light flicker nuisance, in the order of several hours). The value of the factor is calculated based on twelve consecutive values of the $P_{s t}$ index, according to the relationship [5-6]:

$$
\mathrm{P}_{\mathrm{it}}=\sqrt[3]{\frac{\sum_{\mathrm{i=1}}^{12} P_{\mathrm{rti}}^{3}}{12}}
$$


where $P_{s t i}(i=1,2,3, \ldots 12)$ are the consecutive values of short-term light flicker indicators $P_{s t}$.

A specific case of rapid voltage changes are voltage dips, which involve a decrease in the voltage value ranging from $0.9-0.05$ of the rated voltage, followed by the voltage returning to a value near the initial one. They are characterized by depth and duration [5], [7].

Voltage fluctuations result mainly from the presence of consumers in power systems, which receive current, which is alternating in terms of the effective value. Voltage fluctuations impact not only the operation of electrical devices but also the human sight, causing a feeling of tiredness.

According to the applicable regulations, voltage fluctuations shall not exceed $5 \%$ of the rated voltage value for LV systems, while the $P_{l t}$ indicator recorded from a set of 10-minute average voltage effective values shall not exceed $1 \%$ of the $P_{l t}$ for $95 \%$ of the week.

\subsection{Voltage waveform distortion}

Deformed waveforms are analysed using their decomposition into harmonic components, which are sinusoidally variable waveforms with frequencies, which are multiples of the fundamental frequency (first harmonic). In practice, the following are used to evaluate the degree of distortion of voltage and current waveforms in power systems:

- percentage shares of individual harmonics related to the first harmonic are described by the relationships [5]:

$$
\begin{gathered}
U_{\mathrm{h} \% 6}=\frac{U_{h}}{U_{1}} \times 100 \% \\
I_{\mathrm{h} \% 6}=\frac{U_{h}}{I_{1}} \times 100 \%
\end{gathered}
$$

where: $U_{l}$ - fundamental harmonic voltage effective value, $U_{h}$ - voltage effective value of the $h$ harmonic, $I_{l}-$ fundamental harmonic current effective value, $I_{h}$ - current effective value of the $h$ harmonic, $h$ - harmonic order.

- THD (Total Harmonics Distortion) factor described by the relationships [5]:

$$
\begin{aligned}
\mathrm{THD}_{U} & =\sqrt{\frac{\sum_{h=\mathrm{z}}^{\mathrm{n}} U_{h 2}^{2}}{U_{1}}} \times 100 \% \\
\mathrm{THD}_{I} & =\sqrt{\frac{\sum_{h=\mathrm{z}}^{\mathrm{n}} I_{h}^{2}}{I_{1}}} \times 100 \%
\end{aligned}
$$

According to the currently applicable regulations [2-4], the $\mathrm{THD}_{U}$ voltage distortion factor in the case of rated voltage above $110 \mathrm{kV}$ may not exceed $8 \%$.

\section{CASE STUDY}

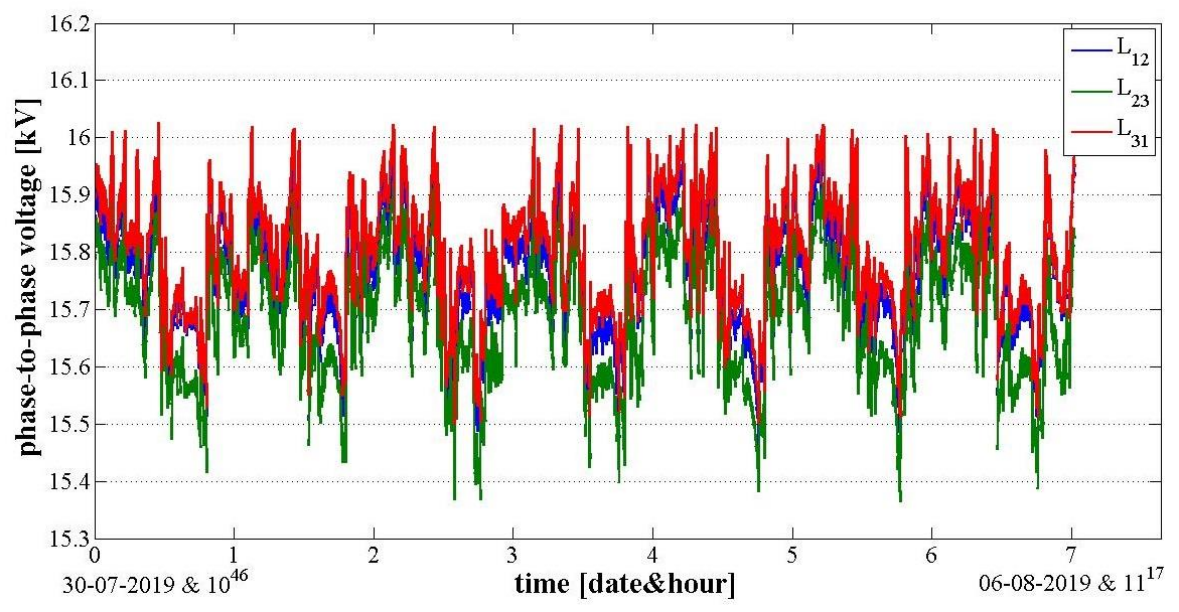

Figure 1. Recorded line-to-line voltage values 
The analysis of the quality parameters of electricity supplying a hospital building commences with measuring the variability of the supply voltage value. All measurements were taken at the hospital supply point, namely, the MV busbars of the transformer station, with a 10-minute averaging period for the measurement results. Figure 1 shows the variability waveform of interfacial (line-to-line) voltages, whereas Figure 2 shows the time waveforms of phase voltages.

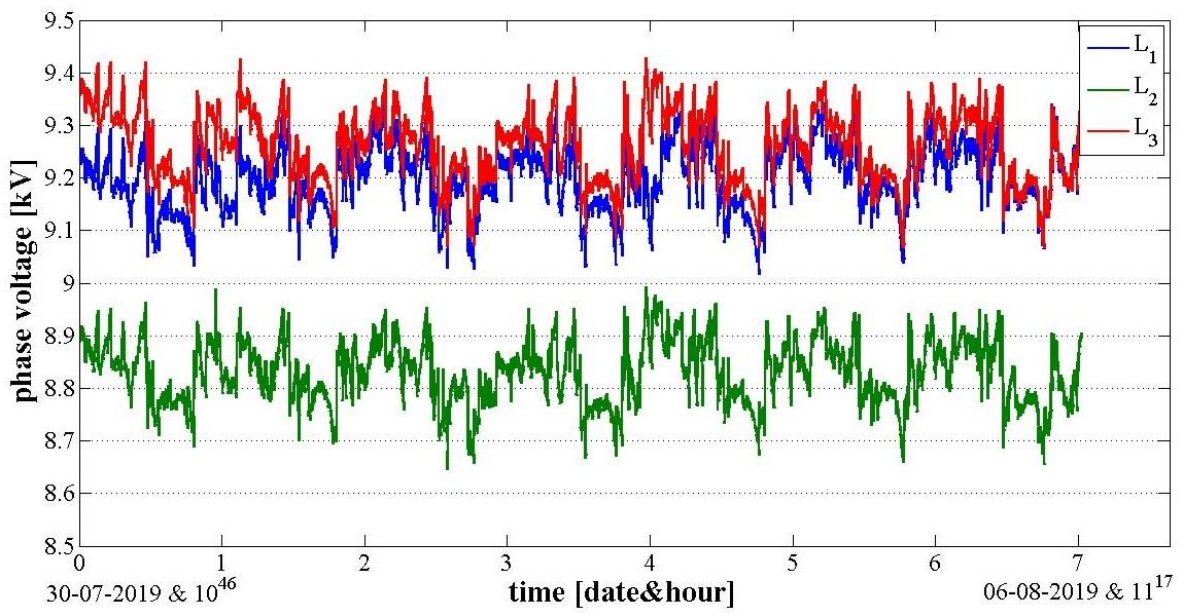

Figure 2. Recorded phase voltage values

The voltage value analysis shows that the hospital is supplied with voltage higher than the rated value. However, these values fall within a range specified by currently applicable regulations, since they do not exceed $10 \%$ of the rated voltage. However, it should be noted that the waveform in Figure 2 clearly indicates a voltage shift in the L2 phase, relative to the voltage in the other phases. This difference is depicted by the waveform of neutral asymmetry factor waveform (shown in Figure 3), the value of which exceed $2.5 \%$.

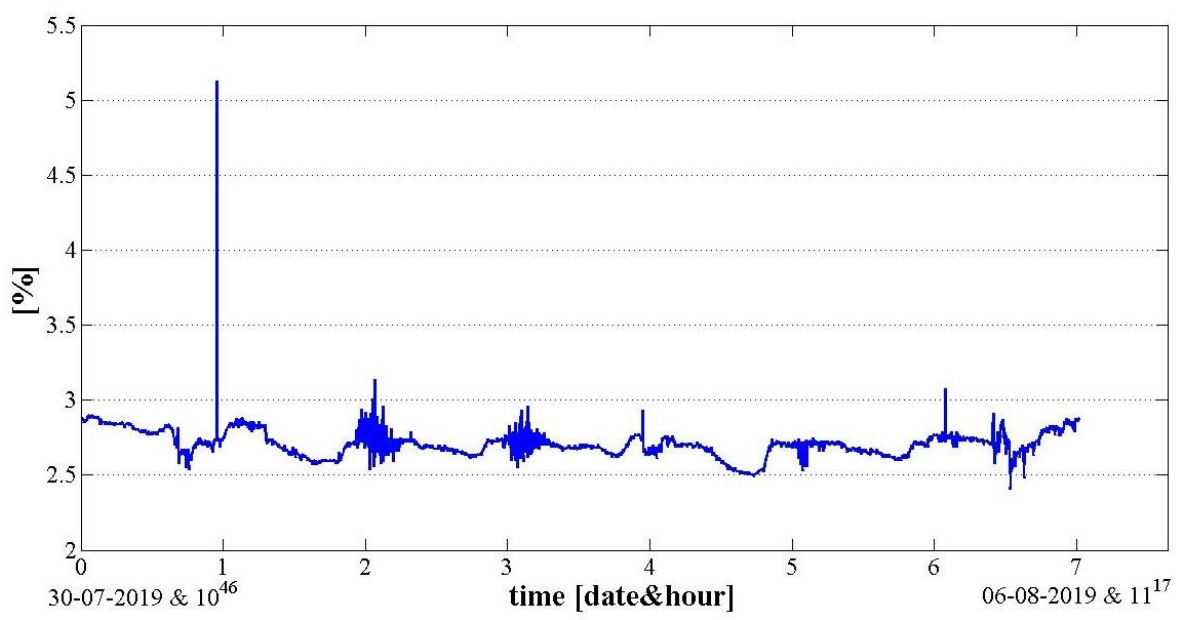

Figure 3. Recorded values of voltage neutral asymmetry

Despite the fact that neutral asymmetry value is not currently standardized, it can cause malfunctioning of certain electronic systems, the three-phase converter systems in particular.

All electrical devices are sensitive (to a greater or lesser degree) to voltage fluctuations. In order to assess whether the improper operation of MRIs results from rapid voltage changes, the maximum and minimum supply voltage values were recorded (Figures 4 and 5). The analysis of these waveforms indicates that 6 voltage dips occurred during the measurements. The correlation of the values shown in Figures 4 and 5 clearly shows that the dips resulted from earth faults present in the hospital supply network (voltage in one, earth-faulted phase significantly decreases its value, with a simultaneous increase of the voltage value in other phases). So many dips over a single week can result in incorrect operation of numerous electrical devices, especially the ones with undervoltage protections, which will manifest 
themselves by unnecessary self-shutdowns (restart) of the devices. However, such interference in a supply network should not have any impact on the malfunctioning of magnetic resonances (often lasting a dozen or so minutes).

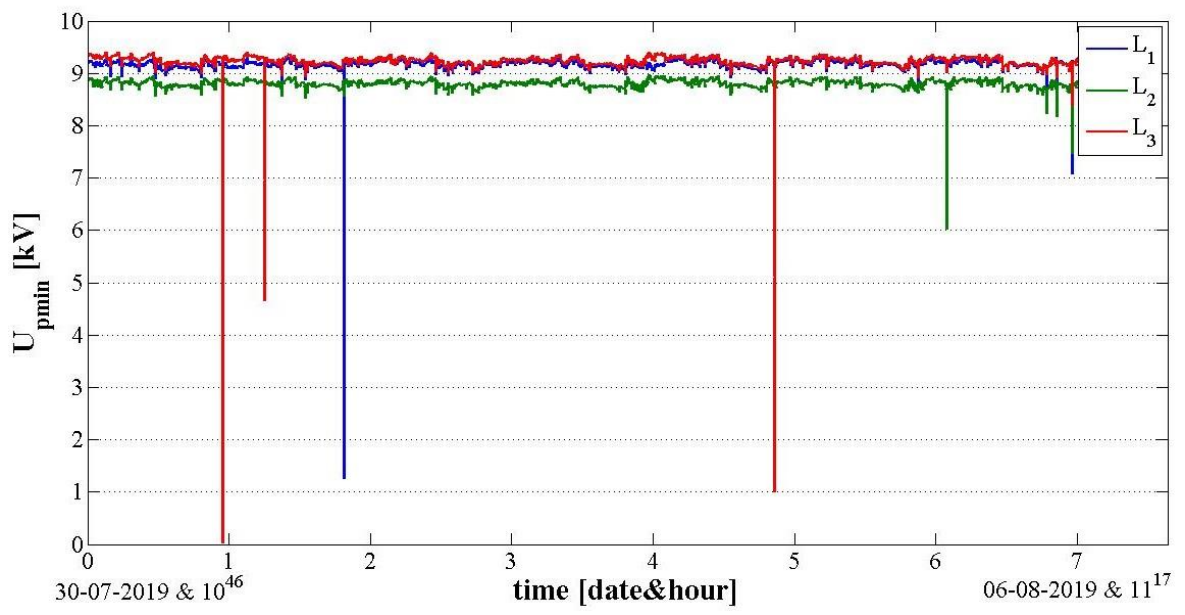

Figure 4. Recorded phase voltage minimum values

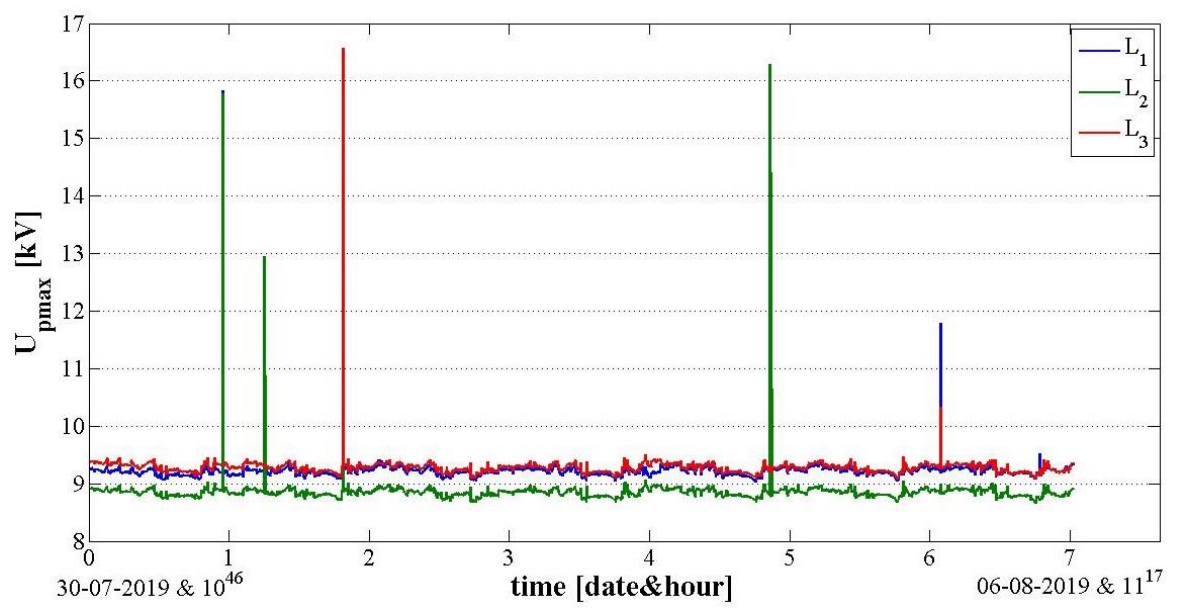

Figure 5. Recorded phase voltage maximum values

The sine waveform-induced supply voltage and current distortion is not without significance on the supplied electrical devices. Based on practical experience, it shall be assumed that a $\mathrm{THD}_{\mathrm{U}}$ below $5 \%$ is deemed normal and there is no risk of device malfunction. The voltage distortion factor value within a range of 5\% to $8 \%$ indicated significant waveform distortion and can result in incorrect operation of some devices. If the THD value exceeds $8 \%$, we are dealing with a very high voltage distortion, with highly probable malfunctioning of equipment supplied with it in such a case.

In the analysed case (Figure 6), the recorded total voltage distortion average value is $2.85 \%$, with a maximum value equal to $6.62 \%$. As a result, a distortion of voltage waveforms due to the sine value can cause improper operation of certain, particularly sensitive, electronic devices.

In order to confirm the aforementioned observations, one should analyse the values of the total current distortion factor. If they exceed $10 \%$ (as per the available results of practical experiments), there is no risk of a malfunction. If the $\mathrm{THD}_{\mathrm{I}}$ value falls within a range of $10 \%$ to $50 \%$, this means a significant distortion of current waveforms, which can cause incorrect operation of certain devices. The temperature of line equipment (supply cables and cables, and transformers) can also occur in such a case. A $\mathrm{THD}_{\mathrm{I}}$ value above $50 \%$ indicates a very high distortion of the waveforms and indicates a highly probable malfunction of the equipment. 


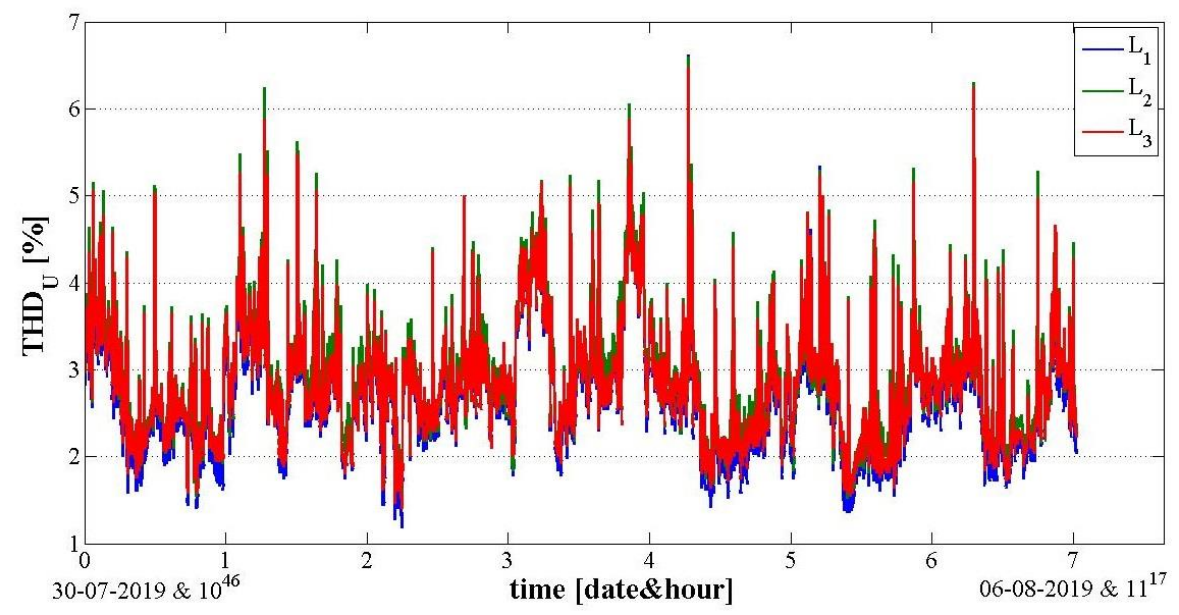

Figure 6. Recorded total voltage distortion factor values

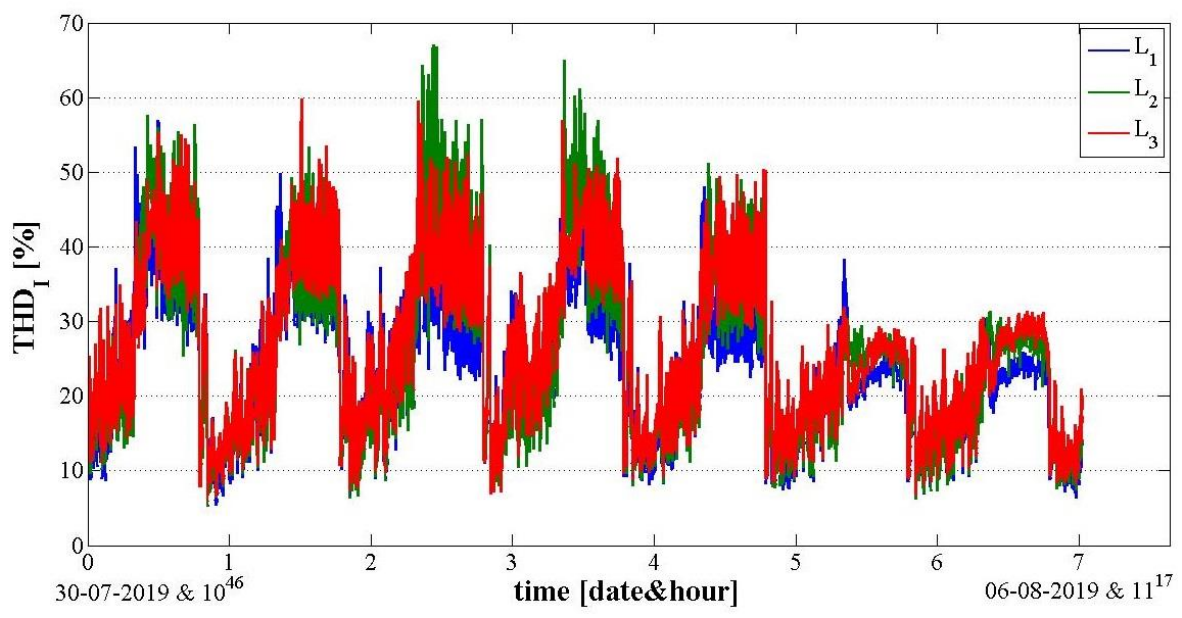

Figure 7. Recorded total current distortion factor values

In the analysed case (Figure 7), the recorded total current distortion average value is $23.72 \%$, with the maximum value equal to $67.12 \%$. In consequence, the recorded current distortions confirm a possibility for the malfunctioning of sensitive electronic equipment. At the same time, it should be noted that the $\mathrm{THD}_{\mathrm{I}}$ variability waveform coincides with the diurnal load variability within the studied systems and rises with increasing load current. This means that the current distortion results from the operation of electrical equipment installed in the hospital.

\section{METHODS FOR ELIMINATING OBSERVED INTERFERENCE}

The first interference observed within the analysed power system was voltage unbalance. The effects of voltage unbalance can be mitigated by:

- a uniform distribution of single-phase consumers onto individual phases,

- installing load balancing equipment,

- thorough interleaving of the phase conductors in overhead supply lines.

Other observed interferences were voltage dips, possibly resulting from switching processes, which can be minimized through the application of hybrid switches constructed on the base of photoconductive switches [8-10]. Unfortunately, in this case, a consumer is unable to individually remove or mitigate them, since they are primarily the outcome of earth faults present within the supply line. The only solutions, albeit a very expensive one, would be to 
switch the hospital onto another, less defective MV line (preferably a power cable), or adding a UPS with appropriate rated power to the supply system.

The last, but not less important interference present in the supply system of the studied hospital is the interference induced by the current and voltage sine waveform. The simplest solution, yet rarely feasible in actual electrical systems is separating sensitive consumers and feeding them from a separate system.

The second solution is applying power system filtration. One of the solutions improving the quality of electricity is using passive filters, with their principle of operation based on the electrical resonance phenomenon [11]. Passive filtration utilizes a resonance of voltages in serially connected chokes with an inductance with capacitors with a capacity $\mathrm{C}$, connected in parallel to the supply grid busbars. The number of filter branches is closely dependent on the number of filtered higher harmonics. Element parameters are selected based on the relationship:

$$
f_{R}=\frac{1}{2 \pi \sqrt{L C}} .
$$

Under resonance, the filter impedance is very low and depends solely on the quality factor of the choke. This makes the filters shunt higher harmonics sources, limiting their impact on the supply mains and other consumers. Filter branch impedance under resonance is sometimes too high. Therefore, it becomes necessary to decrease filter impedance by decreasing choke impedance, which in turn leads to increased capacity, meaning that the network is loaded with a high value capacitive current with fundamental harmonic. This is an adverse phenomenon due to increasing the losses, limiting active power transmission possibilities and additional charges increased for returning capacitive reactive power to the grid. Given the structure of the filter on the existing bank of capacitors intended for compensating reactive power, decreasing impedance is impossible. Passive filtration efficiency depends on the network impedance, which is the basic disadvantage of passive filters. An opportunity to improve the efficiency of LC filters is increasing network impedance through adding additional impedance. Higher network impedance due to the impedance of higher harmonic filtration pulsation makes the filter improve its shunting of a higher harmonic source. This also results in decreased load voltage and network current. Which, in turn, leads to decreased active power of the load and increased losses caused by the deposition of the voltage on additional network impedance.

An additional disadvantage of LC filters is the possible occurrence of parallel resonance (currents) for frequencies lower than for which the filter branch is tuned. The presence of resonance is justified by the impedance of the network of inductive nature and the impedance of the filter of capacitive nature below the tuned frequency. The parallel resonance phenomenon also occurs on as many frequencies as the number of filter branches. This is why it is forbidden to add branches damping higher order harmonics, when it is possible for lower order harmonics to appear within a system.

An advantage of resonant LC filters is the possibility to construct them based on the banks of reactive power compensation capacitors. Although without changing their function, because below a certain resonant frequency, the filter is of capacitive nature. Furthermore, the design of filters based on a capacitor bank protects them against overload caused by the presence of higher harmonics. In the event of incorrect selection of a passive filter system, the network can be excessively overloaded with capacitive reactive current - too high capacity of the capacitor bank. Parallel resonances can occur. In the best-case scenario, the bad selection will result in the filter impedance being too high and them failing to satisfy the specified purpose.

Another method for mitigating power network interference is the application of active filtration [12]. The term active filter means a system power-electronic circuit connected to a system. There are two basic ways for connecting active filters to a supply line/consumer: in parallel and in series. Depending on the type, we can talk about parallel and serial active filters, as well as parallel-current and serial-voltage active filtration. Figure 8 shows models of active filtration systems. The drawings on the left apply to circuits controlled in an open system, whereas the ones on the right to closed-system control. Active filter control methods can be divided due to the manner of identifying undesirable components: fundamental harmonic identification method, integral method and vector method (instantaneous powers).

Serial filtration involves adding an additional, controlled booster voltage $u_{C}$ in the form of a serial (voltage) active power filter to a power supply system, in series with the $e_{S}$ voltage source, over a line with a spectrum of $\mathrm{E}_{\mathrm{S}}=\mathrm{E}_{S}(\mathrm{j} \omega)$. The total voltages for the source $e_{S}$ and the filter system, minus the voltage drop on the supply line impedance $Z_{S}$ is the consumer voltage. Serial filtration enables eliminating higher harmonics of the voltage, balancing and adjusting voltage, as well as compensating voltage drops on the supply line reactance. 
In the case of parallel active filtration (applied previously and more often), the filter system is a controlled booster current source $i_{C}$ serially connected to a consumer. The total of the $i_{C}$ current and the $i_{S}$ current drawn from the supply line gives the $i_{L}$ current drawn by the consumer. As a result (in an ideal scenario and with appropriate control) it is possible to have all components of the $i_{L}$ current, which are undesirable in the $i_{S}$ network current, closed only within the circuit of the consumer-controlled booster current source and not apply load on the supply line. Parallel filtration enables minimizing higher harmonics of the current, compensating the reactive component of the fundamental harmonics current and balancing the load seen on the network terminals.
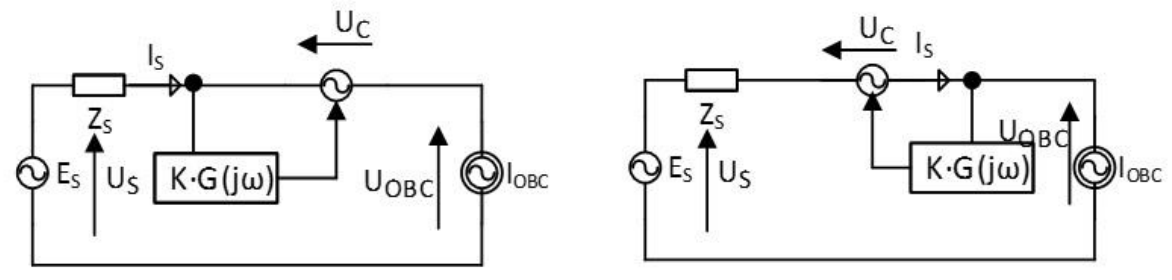

b)
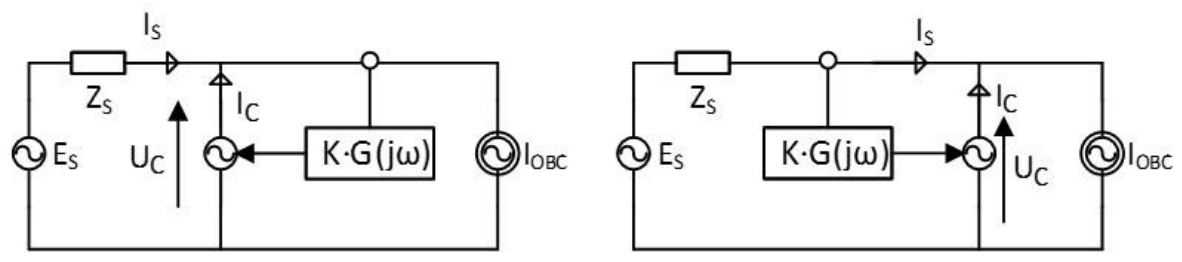

Figure 8. Active filtration system models, a) serial and b) parallel

The main disadvantage of active power filters operating without reactive circuits (supporting the basic functions) is their high apparent power, comparable to the power of compensated components. This involves the flow of consumer full current through a serial active filter circuit or the presence of consumer full voltage on the terminals of the parallel circuit. Due to this, parallel active filters in LV networks require the use of an additional matching transformer and/or constructing the circuits according to special topologies. The name hybrid filter (system) used in the literature covers various connections of active filter circuits with reactive circuits supporting their basic functions, as well as connections between switched capacitor banks, inductive current controllers, etc. In particular, this name applies to the connection between active filtration circuits and LC resonant filters. At the same time, active filter circuits operate depending on the topology of the hybrid system as controlled booster current or voltage sources. Their task is primarily to improve the compensating and filtrating properties of reactive circuits. Whereas adding a reactive circuit to an active filter is aimed at improving its power properties, especially decreasing the voltage on the terminals and/or the flowing current, hence, the required set power of the active filter as well.

\section{CONCLUSIONS}

The paper discusses issues associated with the impact of improper supply voltage parameters on the operation of electronic devices. They are extremely important in terms of electronic devices installed in hospitals, where human health and life often depends on their correct functioning. The elaboration presents the results of electricity parameter measurements for a sample hospital facility, where abnormalities in the operation of such devices were identified after installing an MRI. Possible technical solutions that can directly contribute to eliminating the interference, hence, ensure correct operation of the installed equipment were suggested, based on the recorded parameters, which described the quality of electricity supplying the studied hospital.

\section{REFERENCES}

[1] Suproniuk, M., Skibko, Z., Stachno, A., "Diagnostics of selected parameters of electricity generated in wind power plants", Przegląd Elektrotechniczny, 95, 105-108 (2019).

[2] Regulation of the Minister of Economy of 4 May 2007 on the detailed functioning conditions of the electromagnetic system (Dz. U. of 2007, No. 93 item 623, as amended). 
[3] PN-EN 50160:2010 Voltage characteristics of electricity supplied by public electricity networks

[4] "Distribution Grid Operating and Maintenance Manual" (approved by a decision by the President of UREEnergy Regulatory Office No. DRR-4321-29(5)/2013/MKo4 dated 10 September 2013)

[5] Kowalski, Z.: "Quality of electricity", Wydawnictwo Politechniki Łódzkiej, Łódź (2007)

[6] Hołdyński, G., Skibko, Z., "Parameters describing the quality of electricity", elektro.info, 12, 22-24 (2014)

[7] Hanzelka, Z., "Quality of electricity. Distortions of the effective voltage value ", Wydawnictwa AGH, Kraków (2013)

[8] Kulas, S., Supronowicz, H., Suproniuk, M., Michta, K., "Concept of a single-phase hybrid coupler for power applications ", Przegląd Elektrotechniczny, 92, 37-40 (2016).

[9] Majda-Zdancewicz, E., Suproniuk, M., Pawłowski, M., Wierzbowski, M., "Current state of photoconductive semiconductor switch engineering", Opto-electronics Review, 26, 92-102 (2018)

[10] Suproniuk, M., Kamiński, P., Kozłowski, R., Pawłowski, M., Wierzbowski, M., "Current status of modelling the semi-insulating $4 \mathrm{H}-\mathrm{SiC}$ transient photoconductivity for application to photoconductive switches", OptoElectronics Review, 25, 171-180 (2017)

[11] Strzelecki, R., Supronowicz, H., "Filtering harmonics in AC supply networks", Wydawnictwo „Adam Marszałek", Toruń (1998).

[12] Strzelecki, R., Supronowicz, H., "Power factor in AC supply systems and methods to improve it", Oficyna Wydawnicza Politechniki Warszawskiej, Warszawa (2000). 